\title{
Aprendizagem em Projetos de Trocas Culturais com Uso de Laptops Educacionais
}

\author{
Mixilene Sales Santos Lima1, Maria Lidiana Ferreira Osmundoㅁ, Lavina Lúcia \\ Vieira Lima', Raquel Santiago Freire ${ }^{1}$, Jaiane Ramos Barbosa ${ }^{1}$, Alisandra \\ Cavalcante Fernandes' ${ }^{2}$ José Aires de Castro Filho ${ }^{1}$
}

\author{
${ }^{1}$ Instituto UFC Virtual - Universidade Federal do Ceará (UFC) \\ ${ }^{2}$ Pontifícia Universidade Católica de São Paulo (PUC SP) \\ \{mixilene, lavina, freire, jaiane, alisandra, aires\}@virtual.ufc.br, \\ lidihermana@hotmail.com
}

\begin{abstract}
The present article reports the experience of two projects that made possible cultural exchanges among students making use of the laptop with internet access, besides other digital tools. These projects took place in three schools, in the Northeast part of Brazil, that took part in the program One Laptop per Children (OLPC). This paper will discuss the potential of the technology to provide to the students the experience of different cultures and realities, assisting the learning of school contents. It was noticed that the projects had provided contact and interaction among the participants, such that the cultural exchanges could occur.
\end{abstract}

Resumo. $O$ presente artigo relata a experiência de dois projetos que possibilitaram trocas culturais entre alunos fazendo o uso do laptop com acesso a internet, além de outras ferramentas digitais. Estes projetos ocorreram em três escolas do Nordeste brasileiro participantes do Programa Um Computador por Aluno (UCA). Este trabalho discutirá o potencial da tecnologia para propiciar aos alunos a vivência de culturas e realidades diferentes, auxiliando na aprendizagem de conteúdos escolares. Observou-se que os projetos proporcionaram o contato e a interação entre os participantes, de modo que ocorreram trocas culturais.

\section{Introdução}

O crescente e constante desenvolvimento das tecnologias digitais de informação e comunicação (TDIC) vem modificando a forma como as pessoas pensam, agem e se comunicam. Esses fatores se modificam de acordo com o contexto social [Almeida 2011]. Essas mudanças se fazem pelo uso, cada vez mais frequente, de ferramentas digitais para resolver problemas cotidianos.

A escola como ambiente social de interação, onde a cultura de uma determinada sociedade é reproduzida, vivencia também avanços significativos nas práticas educativas apoiadas pela tecnologia. Estas, por sua vez, vêm mostrando resultados positivos quanto ao seu uso em sala de aula [idem, ibidem]. Entretanto, o uso das TDIC em ambiente escolar deve ser planejado de maneira a adequar as atividades e conteúdos a essas ferramentas, de forma a realizar atividades que integram os envolvidos e não apenas reproduzir práticas tradicionais. Dessa forma, pesquisas recentes mostram que essas ferramentas podem favorecer o contato entre alunos de culturas diferentes, 
visando trocas culturais e novas formas de aprendizagem [Fernandes et al 2009, Lima et al 2010].

Nesta perspectiva, o presente trabalho discutirá o potencial da tecnologia para propiciar aos alunos a vivenciar culturas e realidades diferentes a partir de projetos que auxiliam a aprendizagem de conteúdos escolares. Para tanto, apresentaremos uma breve discussão acerca da relação entre cultura, tecnologias e educação, exemplificando essa relação com algumas experiências anteriores às que aqui serão analisadas, e que servirão como o referencial teórico e como base para nossa reflexão.

\section{Relação entre Educação, Cultura e Tecnologias}

A cultura pode ser entendida de várias formas. Um conceito mais geral desse termo o define como sendo o conjunto de hábitos, costumes e regras de convívio em uma determinada sociedade [Laraia 2000], bem como tudo que aprendemos, ou seja, "é um longo e contínuo processo de seleção e filtragem de conhecimentos e experiências (...), um complexo de ideias e símbolos que passa a integrar nossa própria personalidade" [Machado 2002]. Dessa forma, um gesto pode ser entendido de formas diferentes em comunidades diversas. Em um mundo cada vez mais globalizado e onde as distâncias não se constituem mais em obstáculos para o contato e a interação de pessoas distantes fisicamente, pessoas com hábitos e costumes diversos (e por vezes opostos) podem se relacionar através das TDIC.

Entendendo que essa sociedade solicita indivíduos capacitados para o contato e convívio com pessoas de diferentes culturas, a escola, dentre outras instituições sociais, tem o papel de formar indivíduos preparados para lidar com a diversidade. Isso é algo ainda mais necessário em um país como o Brasil, construído na mistura de etnias e com manifestações culturais tão diversas. Visto que, em seu cotidiano, a escola, oferece meios e manifestações culturais diversificadas que podem ser exploradas como instrumentos pedagógicos, como: questões da comunidades, assuntos de interesse dos jovens, a própria $\mathrm{TV}$, o rádio, além da "prática de intercâmbio entre escolas de diferentes regiões do Brasil e de diferentes municípios de um mesmo estado" [Brasil 1998]. Assim, de acordo com Fernandes et al (2009, p.02)“o professor deve desenvolver também atividades que estimulem seus alunos na discussão de suas identidades culturais, propondo discussões e interação entre culturas e o respeito estabelecido à diversidade".

Dessa forma, as TDIC se tornam ferramentas tanto para o contato entre pessoas distantes geograficamente e de culturas diferentes, como para a construção de conhecimentos acerca dessa troca cultural. Como nas experiências citadas a seguir.

\subsection{Experiências de projetos envolvendo uso de TIDC}

O Projeto 1, Me Perdi e Me achei no Brasil ocorrido em 2009, teve duração de três de meses, já o Projeto 2, Brincando no Brasil, ocorrido em 2010, aconteceu durante dois meses. Ambos foram desenvolvidos com alunos do $4^{\circ}$ ano do Ensino Fundamental de escolas públicas situadas em Fortaleza.

As trocas culturais aconteciam com alunos do mesmo nível de escolaridade, o Projeto 1 com crianças de uma escola da cidade de Villejuif, na França, e o Projeto 2 com alunos de uma escola da cidade Utah, nos EUA, e participantes de um projeto de intercâmbio dos Estados Unidos e da República Dominicana, através de um convênio entre a Universidade Federal do Ceará e a Utah State University (USU). 
Para a realização desses projetos foi utilizados tecnologias como vídeos, fotos, webconferências, nesta, os participantes do Projeto 1 puderam realizar trocas culturais com os alunos franceses, mediados por uma professora da escola da França e fazer decisões sobre a realização de um produto final, enquanto os participantes do Projeto 2 puderam entrar em contato com crianças americanas e conhecer um pouco mais sobre a cultura e as brincadeiras dos Estados Unidos. A comunicação entre as crianças brasileiras e as americanas era mediada pelos alunos do intercâmbio.

O produto final de ambos foi a criação de dois contos digitais, feitos de forma colaborativa, pois todas as atividades foram pensadas e realizadas de forma coletiva, em que valorizassem os aspectos culturais dos envolvidos. A construção dos contos se deu através de uma ideia inicial, pensada e sugerida pelos próprios alunos dos dois países envolvidos em cada projeto, Brasil-França e Brasil-EUA, que juntos decidiram, através de debates e votações, os detalhes e o enredo da história, abordando temas de comum interesse entre os grupos relacionados, com ilustrações e narrativas dos próprios alunos. Após isto, os vídeos animados foram montados pelo grupo PROATIVA (grupo de pesquisa e produção de ambientes interativos e objetos de aprendizagem) e colaboradores.

Tendo conhecimento que o trabalho com projetos utilizando tecnologias nas escolas já é uma realidade, na próxima seção vamos relatar a metodologia de dois projetos que foram investigados neste estudo. Os projetos enfocam a tecnologias como promotora de um trabalho colaborativo, ressaltando a importância das trocas culturais entre os participantes. Logo após, será descrito a metodologia de investigação do trabalho e a análise das atividades entre os participantes discutindo como as tecnologias propiciam aos alunos o contato com culturas e realidades diferentes das suas.

\section{Procedimentos Metodológicos}

Os projetos relatados na próxima seção foram planejados para aconteceram em escolas que receberam o programa $\mathrm{UCA}^{1}$, entendendo que a realização de ambos seria facilitada pela mobilidade das ferramentas, visto que cada aluno pode utilizar os laptops individualmente e na própria sala de aula ou fora dela, sem a necessidade de permanecer somente em um único ambiente.

A pesquisa investigou os dois projetos realizados em três escolas brasileiras, contemplando 88 alunos e 6 professores. Para uma maior eficácia do estudo, optamos por uma pesquisa qualitativa de cunho participativa. Como instrumentos de pesquisas foram utilizados diários de campo, materiais produzidos pelos alunos e registros digitais das páginas virtuais dos projetos.

Para a análise, inicialmente foi feita a classificação dos dados por tipo de dado em ordem cronológica. Em seguida, realizou-se a classificação por temas ligados a aspectos culturais. No tópico seguinte, apresentaremos os resultados de cada um dos projetos separadamente.

${ }^{1} \mathrm{O}$ programa Um Computador por Aluno (UCA) é um projeto piloto do Governo Federal [Brasil 2008], teve início em trezentas escolas no Brasil com objetivo de mudar a forma que a informática educativa é apresentada hoje no país, em que a maioria dos computadores conectados a internet no ambiente escolar ainda ocorre apenas nos Laboratórios de Informática Educativas (LIE). 


\section{Resultados}

A seguir, detalharemos a experiência de cada projeto, mostrando como os alunos, através de TDIC, tinham conhecimento sobre aspectos culturais de seus países.

\subsection{Projeto Nossos Lugares no Mundo}

O projeto Nossos Lugares no Mundo aconteceu durante os meses de maio e junho de 2011 em duas escolas, Monteiro Lobato e Antônio Julião Neto, participantes do programa UCA. Participaram da pesquisa 24 alunos da escola Monteiro Lobato da capital, 26 alunos da escola Antônio Julião Neto do interior do estado e 2 estudantes participantes de um projeto de intercâmbio entre a Universidade Federal do Ceará e a University of Georgia (UGA), dos Estados Unidos. O contato e a interação entre os alunos eram realizados através do blog [http://nossoslugaresnomundo.blogspot.com.br/], onde também puderam trocar informações e experiências. Os estudantes das escolas, juntamente com os universitários americanos, participaram durante as aulas de História, de 2 encontros presenciais por semana, totalizando 11 encontros.

No primeiro encontro de cada semana eram realizadas atividades de discussão entre os alunos brasileiros (de cada turma) e os estudantes americanos sobre os seguintes temas: local de habitação, pontos turísticos, fatos históricos, literatura e festas típicas. Após os debates, os alunos das escolas realizaram atividades de produção em equipes, tais como: apresentações em PowerPoint, criação de textos, inclusive de um cordel. Em grupo de 5 alunos, os brasileiros realizavam as atividades utilizando o laptop educacional, a fim de contribuir com a pesquisa e, consequentemente, a aprendizagem acerca dos temas abordados. Por exemplo, em uma das atividades os estudantes americanos e brasileiros pesquisavam e apresentaram os monumentos de suas cidades explicando sua importância histórica. Ao final das atividades, era produzido por cada turma um material multimídia ou um texto escrito conjuntamente pelos grupos, para ser postado no blog pela equipe de coordenação do projeto.

Durante o segundo encontro de cada semana, as turmas tinham oportunidade de visualizar no blog o que haviam feito no encontro anterior, ou seja, ver e comentar as atividades postadas de ambas as turmas promovendo interação entre os alunos. Dentre as atividades realizadas destacaremos aspectos que foram relevantes nas discussões entre as turmas, divididos por temas, recorrentes durante a análise.

\section{Identificação de semelhanças e diferenças entre as culturas}

Ao analisar os dados registramos que, em diversas atividades, os alunos identificaram aspectos semelhantes entre as cidades representadas, Fortaleza e Barreira. Exemplificamos aqui essa afirmação, transcrevendo um diálogo feito nos comentários do blog do projeto, ao qual se referia ao local de moradia dos alunos. Ressaltamos que os nomes foram suprimidos para garantir a privacidade e preservamos a escrita original dos alunos.

\footnotetext{
Aluno 1 disse [oculto para submissão]:oi Aluno 2 eu me chamo 1 e eu gostei muito do seu comentario.na minha rua tem muitos buracos e lama mas la é muito legal la tem também uma sorveteria tem uma ingreja que eu vou eu já sou do conjunto de jovem.

Aluno 2 disse [oculto para submissão]: OI 1 que legal eu tambem sou do cojuto jovem La da Igreja beijos
} 
Observa-se a percepção dos alunos em descrever sua rua, mesmo esta não possuindo boas condições, aproveitam também para destacar a semelhança de ambos participarem de certa atividade, no caso, encontros de grupo da igreja.

No exemplo a seguir, é possível ver a curiosidade das crianças e a percepção de semelhanças e diferenças quanto a ambientes de lazer que existem em suas cidades.

Aluna 3 disse: eu gostei muito da ponte metalica,mas que pena que eu nunca fui lá,aqui naõ tem a ponte metalica mas aqui tem açudes,aqui tem praça mas naõ é ingual a essa dai, aqui naõ temos museus mas tem o de redençaõ, tem o crás que as criaças se apresenta.

Aluno 4 disse: Os comentarios estão ótimos,[Aluno 3], aqui não tem o CRAS, mas tem o CSU que é iqual. No CSU, é parecido, tem piscina, futsal, futebol, claro que é o futebol brasileiro. No CRAS daqui, as crianças tanbém de vez em quando se apresentam, é muito legal. tchau

Em diversos momentos os alunos identificaram semelhanças e diferenças entre suas realidades. Isto acontecia durante as pesquisas, apresentações e, principalmente nas interações através dos comentários feitos no blog. Os alunos sempre respondiam os comentários dos outros, trocando informações sobre os assuntos postados favorecendo trocas e conhecimento sobre a cultura de ambos os participantes. Abegg, Bastos e Müller (2010) defendem que o trabalho colaborativo em rede mediado pela TDIC potencializa a formação social, favorece o crescimento do grupo e, estimula o trabalho em conjunto de modo que produzam coletivamente o conhecimento. As ferramentas digitais como blog, site e outros que possibilitam a colaboração, a partir da mediação docente, oportunizam os estudantes a serem co-autores do conhecimento em lugar de serem apenas consumidores de informações.

\section{Curiosidade sobre a outra cultura}

Percebemos também que o aluno não apenas entende que a interação pode ser feita, ao realizar comentários sobre a atividade da outra turma, como também vai além do simples comentário e propõe continuidade à interação, ou seja, a curiosidade estava aguçada, o desejo em ter informações sobre o outro era bem expressivo, além de estarem preocupados em saber o que a outra turma achava de seus comentários, bem como, dos lugares apresentados.

\footnotetext{
Aluno 5 disse: oi gente! O que vocês fizeram?,nós do $5^{\circ}$ ano,quando fomos apresentar o que era cordel aos americanos tivemos uma participação do Ari Bandeira,um cordelista daqui de [...].Mas amigos fiquei muito supresa com o cordel de vocês. Ficou ótimo!!!.Beijos,tchau.
}

Aluno 6 disse:Parabens pelos versos.Eu gostei muito!!Quando lei os versos Eu queria muito saber das festa de vocês juninas como e as bricadeira de vocês são legais?

Aluno 7 disse: Oi pessoal!!! gostei da mistura das festas pessoais.Qual é a comida tipica dai de [...]? nossa festa foi muito perecida com a de vocês. Nosso arraiá é segunda-feira e o de vocês?

Entendemos que ações como estas demonstram interesse dos alunos pelo outro, bem como, a espontaneidade de se colocar como sujeito do comentário, sabendo que, tendo um laptop a sua disposição, poderiam responder às possíveis respostas aos comentários demonstrando curiosidade pela outra cultura, pois apesar de morarem em um mesmo estado e possuírem culturas semelhantes "a participação do indivíduo em sua cultura é sempre limitada; nenhuma pessoa é capaz de participar de todos os elementos de sua cultura." [LARAIA 2000 p.82], mostrando assim que, a curiosidade é reconhecimento desses elementos culturais, bem como ao fazer questionamentos sobre a 
realização das atividades na outra escola mostra o interesse de saber se as atividades acontecem da mesma forma.

\section{Valorização da cultura}

Durante o contato das crianças por comentários no blog, a valorização da própria cultura foi bem destacada, como é possível observar nos exemplos abaixo. Em meio a interação, ambas as turmas ressaltaram que, embora não tivessem os mesmos lugares e ambientes nas duas cidades, cada uma tinha seus benefícios e demonstravam curiosidade de conhecer a cidade do outro.

Aluno 8 disse: eu gostei muito da [...],mas que pena que eu nunca fui lá,aqui naõ tem a [...] mas aqui tem açudes,aqui tem praça mas naõ é ingual a essa dai, aqui naõ temos museus mas tem o de [...], tem o crás que as criaças se apresenta.

Aluno 9 disse: Oi [Aluno 8]que pena que você não conhece a Ponte Metálica. Queria um dia que você pudesse vir aqui conhecer. Eu vou te contar como ela é: bem, ela tem outro nome que É Ponte dos Ingleses todo mundo vai lá, sempre à tardinha, com a família ou amigos para ver o por-do-sol, tomar sorvete, ver as águas bater nas pedras.

Isto nos faz perceber que os alunos compreendem as diferenças entre as cidades e percebem que nenhuma das cidades é melhor ou pior que a outra. Os PCN destacam que "fortalecer a cultura de cada grupo social, cultural e étnico que compõe a sociedade brasileira, promover seu reconhecimento, valorização e conhecimento mútuo, é fortalecer a igualdade, a justiça, a liberdade, o diálogo e, portanto, a democracia" [BRASIL 1998 p 132]. Nesse sentido, perceberam que cada uma das cidades tem suas características e suas peculiaridades, denotando assim, um apreço por onde moram.

\section{Experiência com o projeto}

Ao final dos projetos, os alunos comentaram sobre a experiência em participar de um projeto desse gênero. É possível observar a satisfação deles e o reconhecimento de ter aprendido durante as atividades realizadas.

Aluno 10 disse: OLA!!!Eu queria conta como foi essa esperiencia pra mim,eu achei legal,porquê aprendei coisas novas,melhor coisas da capital do meu estado,pude conhecer novas pessoas. Foi muito interessante. Beijos.Tchaw

Aluno 11 disse: Gostei muito do projeto nossos lugares no mundo ! foi muito legal a aula hoje pois aprendemos muitas coisas que não sabiamos.

Aluno 12 disse: Eu gostei muito de fazer parte do projeto nossos lugares no mundo, pois eu estou muito feliz por que eu conheci outras pessoas. eu estou gostado muito de conhecer todos voces eu agradeço a tia (...) muito esta oportunidade. Espero ver voces de novo.Eu não fui na viagem para Fortaleza mas a minha turma foi. Gostei muito de ter reencontrado vcs neste museu digital. Até a próxima!!!

Diante destes relatos, observamos a importância da tecnologia para apoiar projetos que promovam a interação e a colaboração entre os alunos. Assim como Fernandes et al (2009) e Lima et al (2010) mostraram, a realização de projetos só é possível através do envolvimento dos professores e dos alunos.

\subsection{Projeto Vizinhança Americana/American Neighborhood}

O projeto Vizinhança Americana aconteceu entre os meses de outubro e novembro de 2011 entre uma turma da escola da cidade São Gonçalo, participante do projeto UCA, e uma turma de uma escola norte americana da cidade de Logan, em Utah. Participaram 38 alunos brasileiros do $5^{\circ}$ ano e uma turma americana do ano equivalente. Os 
encontros eram realizados uma vez por semana, com duração de aproximadamente duas aulas. O contato e a interação entre os alunos eram realizados através do site [https://sites.google.com/site/usubrasilproject/home] em que as crianças de ambas as turmas puderam trocar informações e experiências, além de exibir fotos e vídeos.

O projeto teve um total de 6 encontros, nos quais, além dos laptops do programa UCA, que eram utilizados inclusive para acessar o site criado para o projeto, fazia-se uso de webconferências entre os alunos brasileiros e norte americanos com a ajuda dos professores e pesquisadores envolvidos, visando favorecer a interação entre as duas salas de alunos.

No início de cada encontro eram realizadas atividades de discussão entre os alunos brasileiros sobre os seguintes temas: alimentação, dinâmica na hora da merenda escolar, música, principais artistas e ritmos nordestinos. Após os debates, os alunos das escolas realizaram atividades de produção em equipes, tais como: apresentações em PowerPoint, criação de textos e vídeos. Durante as webconferências, ambas as turmas, tanto do Brasil quanto dos Estados Unidos, apresentavam o que haviam produzido no Power Point e no Prezi, além de realizarem apresentações orais e artísticas. O intuito era discutir sobre semelhanças e diferenças entre as culturas dos dois países, além de procurar inserir o conteúdo final dessas atividades do site destinado ao projeto, de forma que os alunos americanos pudessem ver, a partir da visão das crianças, o que há no Brasil sobre esses assuntos.

Em praticamente todas as atividades realizadas, os alunos trabalharam em equipes, seja para produzir vídeos referentes à dinâmica da hora do lanche ou textos para serem postados no site. Além disso, algumas produções partiram do desejo próprio dos alunos, como a ideia de produzir poesias, gravar um vídeo em que alunos tocam violão, cantam um repente e dançam baião, estilos musicais tipicamente nordestinos.

Foi possível observar a aprendizagem dos alunos no engajamento durante a realização das atividades do projeto apoiado pelo uso dos laptops. Seguem alguns exemplos que justificam nossa afirmação, divididos por temas.

\section{Identificação de semelhanças e diferenças entre as culturas}

A partir de registros feitos no diário de campo durante a realização do projeto, identificamos que os alunos da escola cearense conseguiram fazer distinções entre as culturas brasileira e norte americana, no caso mais específico sobre a alimentação dos dois países, pois comentaram sobre a diferença dos hábitos alimentares. Além disso, ao serem apresentados a vegetação norte americana durante uma webconferência, os alunos brasileiros puderam associar as árvores mostradas, pinheiros, com as árvores artificiais usadas em época de natal, como está descrito logo abaixo:

Relato 1 - diário de campo: Então fizemos a dinâmica de apresentação, na qual cada aluno falava seu nome e uma comida que gosta. O colega do lado repetia o nome do amigo, sua comida e falava seu nome e a comida que gostava, e assim por diante. Todos participaram, e aqueles alunos que não lembravam das comidas dos colegas, recebiam a ajuda dos outros. As comidas mais faladas foram sorvete, lasanha, pizza e pastel, mas outros como bolo, mousse, arroz e feijão e até rapadura, também foram falados. Ao final, perguntei a eles se achavam que nos Estados Unidos as pessoas também comiam aquelas coisas. Eles disseram que comiam algumas, mas outras como rapadura, não. E disseram que iam perguntar pra eles.

Relato 2 - diário de campo: Os alunos daqui gostaram bastante e se interessaram em saber quais os animais que havia lá (-Lá tem urso polar? Lá tem esquilo, né?) e sobre os pinheiros, que identificaram logo como sendo árvores de Natal. 
O autor Laraia [2000] destaca:

cada sistema cultural está sempre em mudança. Entender esta dinâmica é
importante para atenuar o choque entre as gerações e evitar comportamentos
preconceituosos. Da mesma forma que é fundamental para a humanidade a
compreensão das diferenças entre povos de culturas diferentes, é necessário
saber entender as diferenças que ocorrem dentro do mesmo sistema. Este é o
único procedimento que prepara o homem para enfrentar serenamente este
constante e admirável mundo novo do porvir (p. 105)

Com estes relatos, vimos que apesar desses alunos morarem em lugares bem distintos, afinal Brasil e Estados Unidos possuem características diferentes em vários aspectos, isso mostra uma visão não preconceituosa e que eles reconhecem que existem semelhanças e também diferenças em cada lugar, como é o caso da rapadura, alimento típico do nordeste brasileiro que é facilmente reconhecido como uma comida diferente da dos norte americanos.

\title{
Curiosidade sobre a outra cultura
}

Em todas as atividades percebemos o interesse em conhecer aspectos da cultura do outro (da cultura brasileira por parte dos alunos norte americanos e vice-versa). Isso se deu na formulação de perguntas para serem respondidas pelos colegas do outro país, como vemos no exemplo abaixo. Embora nem todas as perguntas tenham sido respondidas no site, algumas respostas foram dadas durante as webconferências.

\author{
Alunos 1, 2 e 3 disseram: \\ "01. Como é morar aí? \\ 02. Como está sendo o projeto para vocês? \\ 03. Quais são os cantores que vocês mais gostam? \\ 04. Quais são os tipos de comida que vocês mais gostam? \\ 05. Como é o nome do(a) professor(a) de vocês? \\ 06. Vocês gostaram da gente? \\ 07. Gostamos dos artistas estrangeiros. E vocês, gostaram dos artistas \\ brasileiros?"
}

Além dos questionamentos feitos, os alunos sempre queriam explicar detalhes sobre suas culturas, como no caso que segue, em que o aluno 4, de Logan, esclarece um fato antes da realização de uma webconferência:

\begin{abstract}
Aluno 4 disse: "When you see us tomorrow you might think we have gone a little crazy. That is not the case! It's just our hair! Tomorrow is Crazy Hair Day sponsored by our Student Council. This day includes a study of hair styles from other countries, donations of hygiene products, and, yes, crazy hair!! So don't be surprised when you see us!!!".(Tradução: Quando vocês forem nos ver amanhã talvez pensem que ficamos um pouco loucos. Esse não é o caso! É apenas nossos cabelos! Amanhã é o dia do cabelo maluco (Crazy Hair Day) patrocinado pelo nosso conselho de estudantes. Esse dia inclui um estudo sobre os estilos de cabelos de outros países, doações de produtos de higiene, e sim... cabelos malucos!! Então não se surpreendam quando nos verem!!!).
\end{abstract}

Durante o projeto, pôde-se notar facilmente o interesse dos alunos em participar, através do entusiasmo, da autonomia dos mesmos na realização das atividades e também a partir da concentração e imersão dos alunos brasileiros durante as apresentações dos alunos norte americanos.

\section{Valorização da cultura}

Após serem instigados pelas pesquisadoras a falarem o que sabiam sobre alimentação e artes, os alunos da escola brasileira se sentiram motivados a pesquisar e a apresentar sobre a cultura nacional. Em comentários retirados do site destinado ao projeto, alunos 
ressaltam a boa qualidade dos alimentos nacionais e também escrevem sobre a existência de artistas brasileiros.

\begin{abstract}
Aluno 5 disse: “(...)Eu tenho uma curiosidade: aí tem tomateiro? Aqui no Brasil é muito comum. É tão gostoso, uma delícia. Uma pergunta: eles gostariam de vir aqui no Brasil?"
\end{abstract}

Aluno 6 disse: "Olá meu nome é 6, Aqui no Brasil é muito legal. Aqui tem cantores, atrizes, ator, poetas, muitas coisas. O nome da minha professora é[...]. A comida daqui é muito gostosa, tem verduras gostosas, frutas gostosas. Aqui tem muitas coisas legais. Nós todos temos um computador para falar com vocês. Aqui faz muito calor, às vezes faz frio, mas é muito difícil. Vocês já conheceram o Brasil?"

Com os exemplos acima, notamos uma variação de assuntos abordados que demostram a valorização dos alunos ao descreverem coisas simples de seu país, como é o caso do tomateiro. Além de falarem sobre o que é característico no Brasil, os artistas, e ainda destacarem sobre o clima da sua cidade. Para que isso aconteça, durante a realização dos projetos é muito importante que os alunos sejam estimulados "a pensar de forma crítica ao refletir sobre a própria cultura e ao propor-se a conhecer aspectos de uma cultura diferente." [Lima, 2011].

\title{
Experiência com o projeto
}

Os alunos, desde o primeiro momento, quando foram apresentados ao projeto, demonstraram interesse e motivação em participar, ou seja, o projeto foi bem aceito pela turma. Dessa forma, os relatos abaixo mostram que expectativas foram atendidas, os alunos terminaram o projeto de forma satisfatória, com resultados proveitosos na aprendizagem, engrandecendo o conhecimento sobre a própria cultura e ampliando conhecimentos, pois vivenciaram novas experiências e entraram em contato com uma nova cultura. Como podemos ver nos relatos abaixo descritos:

\footnotetext{
Alunos 6, 7 e 8 disseram: "Eu gostei muito da aula do intercâmbio e quero que repita muitas vezes. Eu gostei muito porque vocês são legais e também eu gosto dos Estados Unidos porque aí deve ser legal.Fim."

Aluno 9 disse: "O projeto Utah é muito legal. Desde o dia que a [pesquisadora 1] veio, mas não só ela, que vem as amigas dela da [universidade] também, esse projeto faz a gente aprender muita coisa. Sobre pesquisa na internet, piadas, poesias, sobre cantores, histórias, e a gente pesquisa isso tudo no uquinha. É muito legal pesquisar.
}

Pode-se notar, a partir dos relatos, a satisfação dos alunos em participar do projeto e em conhecer novas pessoas e saber sobre outra realidade. Ressaltam ainda o motivo do interesse quando escrevem sobre o que realizaram durante o projeto: a aprendizagem obtida com pesquisas na internet. Outras experiências mostram que o trabalho com projetos que utilizam as ferramentas digitais favorece para que os alunos criem hábitos de pesquisa e saibam trabalhar colaborativamente, principalmente quando planejado com os professores e usado em parceria com o currículo [Lima et al 2011].

A análise dos dados e depoimentos colhidos junto aos envolvidos nos projetos permitiu reunir algumas contribuições que foram consideradas relevantes para o processo de ensino e aprendizagem durante a utilização dos laptops dentro do programa UCA. A seguir, apresentaremos nossas conclusões acerca das análises aqui realizadas.

\section{Conclusões}

Os dois projetos, embora realizados de forma diversificada, tiveram resultados semelhantes. Todos os envolvidos puderam entrar em contato com uma nova cultura, 
absorvendo novos conhecimentos e gerando aprendizagem. Motivaram-se tanto para aprimorar os conhecimentos sobre a própria cultura, visando realizar boas apresentações, quanto para conhecer uma cultura nova.

Pode-se perceber que novas práticas de ensino e aprendizagem foram experimentadas pelas escolas participantes dos projetos, o que facilitou a partir do programa UCA. Assim, durante o desenvolvimento dos projetos foi identificado o engajamento dos professores em contribuir com as atividades de modo que alunos pudessem ter o maior acesso possível ao uso das TDIC. Os estudantes utilizaram editores de texto para produzir textos coletivos e apresentações; câmera fotográfica para registrar ações e tarefas; laboratório de informática como suporte das atividades e laptops nas aulas de campo. Ou seja, foram diversas as ferramentas utilizadas e as mídias produzidas.

Estas práticas, enfocadas no uso de tecnologias, auxiliaram a realização de projetos levando à produção de conhecimentos significativos e críticos, pois durante a realização dos mesmos foram utilizadas TDIC de modo que os alunos pudessem transpor a reprodução e produzir o próprio conhecimento, com autonomia e espírito investigativo. Além disso, os projetos promoveram atividades que favoreceram o trabalho em equipe e o contato dialógico com os alunos de outras cidades e países, proporcionando trocas culturais. Os participantes puderam identificar semelhanças e diferenças entre suas culturas, o que possibilitou a formação de espaços para problematizar, dialogar, pesquisar, elaborar e produzir conhecimento.

O uso da TDIC nos projetos descritos pôde fazer com que os alunos transitassem culturalmente por realidades diferentes, contribuindo na diminuição de barreiras geográficas e temporais. Desta forma, a incorporação da tecnologia na escola resulta em uma nova relação no meio educacional. O processo educativo, mediado por equipamentos que permitem a comunicação e a transmissão de informações faz gerar conhecimento. A distância não é mais um problema, pois a comunicação está acontecendo. Dessa forma, essa nova geração da educação, a que se utiliza do meio digital, é habilidosa em fazer "conexão entre as pessoas" com propósitos de ensinoaprendizagem [Collis, 1995:09].

Os processos de aprendizagem foram marcados por aqueles momentos em que professores e alunos engajaram-se mutuamente na realização das atividades. Dentre estas destacam-se: discussão em grupo para decisões das atividades e temáticas relacionadas aos projetos; participação na construção de ambientes virtuais (site ou blog); produção de texto em grupo, tanto no papel como no computador, sobre as temáticas dos projetos; produção de vídeos referente à dinâmica e distribuição do lanche na escola, ao estilo musical dos participantes e à danças nordestinas; criação e elaboração de apresentações sobre o resultado dos projetos; e estudo da língua norte americana a partir de músicas em inglês.

Os projetos aqui destacados puderam influenciar na aprendizagem dos alunos engajados, fazendo com que seus conhecimentos pudessem ser ampliados, visto que tiveram contato com realidades diferentes. Além disso, essas experiências só foram possíveis de se realizar devido ao uso das TDIC, pois sem a utilização das mesmas a comunicação e o contato com o exterior não aconteceria de modo instantâneo, além da do material produzido poder ser acessado via internet. Isto mostra o potencial em que as TDIC têm na sociedade atual.

Desta forma, com a análise e a realização da pesquisa é possível afirmar que os trabalhos desenvolvidos nas escolas proporcionaram ganhos para professores e alunos, e 
que o trabalho com as TDIC pôde ser realizado com sucesso. Assim, espera-se que este trabalho possa contribuir para discutir a importância do desenvolvimento de projetos culturais nas escolas e que esta realização possa ser potencializada pelo uso de ferramentas digitais, como no caso dos projetos aqui realizados.

\section{Referências}

Abegg, Ilse; Bastos, F. P. e Müller, F. M. (2010) "Ensino-Aprendizagem Colaborativo mediado pelo wiki do Moodle", In: Educar em Revista. http://ojs.c3sl.ufpr.br/ojs2/index.php/educar/article/viewFile/13129/13530. Junho.

Almeida, M. E. B e Valente, J. A. (2011) "Tecnologias e Currículo: trajetórias convergentes ou divergentes?" São Paulo: Paulus.

Brasil. MEC/SEF. (1998) "Parâmetros Curriculares Nacionais: Quinto e Oitavo ciclos do Ensino Fundamental”. Brasília, DF,10v.

Brasil. (2011) "Um Computador por Aluno: a experiência brasileira", http://bd.camara.gov.br, Junho.

Collis, Betty. (1995) "Tele-learning in a Digital World: the future of Distance Learning”. London: International Thomson Computer Press.

Fernandes, A. C., Freire, R. S., Castro Filho, J. A., Lima, L. L. V., Barbosa, J. R.(2009) "Interligando Mundos, Conhecimento e Cultura: Uma experiência on line entre alunos do Ensino Fundamental do Brasil x Japão", in: Virtual Educa, v. 1.

Harasim, L. (1989) "On-Line Education: A New Domain". in: Mindweave: Communication, Computers and Distance instruction, Edited by Mason, R., Kaye, A. Oxford: Pergamon.

Laraia, R. Barros (2000) "Cultura - um conceito antropológico" 13 ed. Jorge Zahar Editor Rio de Janeiro, RJ, 13 ed.

Lima, L. L. V., Barbosa, J. R., Fernandes, A. C., Freire, R. S., Castro Filho, J. A., Pequeno, M. C. (2010) "Me perdi e me achei no Brasil: Multiculturalismo e produção colaborativa de conteúdos digitais na escola", in: XVI Workshop Sobre Informática na Escola - WIE - TICs e educação para inclusão social e tecnológica e promoção da cidadania, páginas 1197-1205. Anais.

Lima, L. L. V., Lima, Lucas. V. de; Barreto, D., Fernandes, A. C., Castro Filho, J. A. (2011) "Interações multiculturais mediadas por computador: as percepções de dois participantes sobre o projeto Nossos Lugares no Mundo", in: XVII Workshop Sobre Informática na Escola - WIE - Informática na educação para a Democratização do Conhecimento, páginas 1924-1934. Anais.

Machado, C. G. (2001) "Multiculturalismo: Muito Além da Riqueza e da Diferença". Rio de Janeiro, DP\&A.

Nascimento, K. A. S. Do., Silva, M. A. da., Melo, M. B. O. de., Barbosa, J. R., Castro Filho, J. A. (2011) "Programa UCA no Estado do Ceará: Caminhos Percorridos, 
Lições Aprendidas", in: $17^{\circ}$ Workshop de Informática na Escola. Informática na Educação para a Democratização do Conhecimento, páginas 1207-1215, v. 22.

Vygotsky, L.S. (1984) “A Formação Social da Mente”, São Paulo: Martins Fontes. 